\title{
Practice makes perfect
}

Citation for published version (APA):

Rienäcker, F., Jacobs, H. I. L., Van Heugten, C. M., \& Van Gerven, P. W. M. (2018). Practice makes perfect: High performance gains in older adults engaged in selective attention within and across sensory modalities. Acta Psychologica, 191, 101-111. https://doi.org/10.1016/j.actpsy.2018.09.005

\section{Document status and date:}

Published: 01/11/2018

DOI:

10.1016/j.actpsy.2018.09.005

Document Version:

Publisher's PDF, also known as Version of record

\section{Document license:}

Taverne

\section{Please check the document version of this publication:}

- A submitted manuscript is the version of the article upon submission and before peer-review. There can be important differences between the submitted version and the official published version of record.

People interested in the research are advised to contact the author for the final version of the publication, or visit the DOI to the publisher's website.

- The final author version and the galley proof are versions of the publication after peer review.

- The final published version features the final layout of the paper including the volume, issue and page numbers.

Link to publication

\footnotetext{
General rights rights.

- You may freely distribute the URL identifying the publication in the public portal. please follow below link for the End User Agreement:

www.umlib.nl/taverne-license

Take down policy

If you believe that this document breaches copyright please contact us at:

repository@maastrichtuniversity.nl

providing details and we will investigate your claim.
}

Copyright and moral rights for the publications made accessible in the public portal are retained by the authors and/or other copyright owners and it is a condition of accessing publications that users recognise and abide by the legal requirements associated with these

- Users may download and print one copy of any publication from the public portal for the purpose of private study or research.

- You may not further distribute the material or use it for any profit-making activity or commercial gain

If the publication is distributed under the terms of Article $25 \mathrm{fa}$ of the Dutch Copyright Act, indicated by the "Taverne" license above, 


\title{
Practice makes perfect: High performance gains in older adults engaged in selective attention within and across sensory modalities
}

\author{
Franziska Rienäcker ${ }^{\mathrm{a}, *}$, Heidi I.L. Jacobs ${ }^{\mathrm{b}, \mathrm{c}}$, Caroline M. Van Heugten ${ }^{\mathrm{a}, \mathrm{b}}$, \\ Pascal W.M. Van Gerven ${ }^{\mathrm{d}}$ \\ a Department of Neuropsychology and Psychopharmacology, Faculty of Psychology and Neuroscience, Maastricht University, Maastricht, the Netherlands \\ ${ }^{\mathrm{b}}$ School of Mental Health and Neuroscience, Department of Psychiatry and Neuropsychology, Faculty of Health, Medicine and Life Sciences, Maastricht University, \\ Maastricht, the Netherlands \\ ${ }^{\mathrm{c}}$ Division of Nuclear Medicine and Molecular Imaging, Department of Radiology, Massachusetts General Hospital/Harvard Medical School, Boston, MA, USA \\ ${ }^{\mathrm{d}}$ School of Health Professions Education (SHE), Department of Educational Development \& Research, Faculty of Health, Medicine and Life Sciences, Maastricht University, \\ Maastricht, the Netherlands
}

\section{A R T I C L E I N F O}

\section{Keywords:}

Aging

Selective attention

Distraction

Sensory modality

Practice

\begin{abstract}
A B S T R A C T
Selective attention has been found to decline with aging, possibly depending on the sensory modality through which targets and distractors are presented. We investigated the capacity of older adults to improve performance on visual and auditory selective attention tasks. 31 younger (mean age $=22.8$ years, $S D=2.1$ ) and 29 older participants (mean age $=69.5$ years, $S D=5.8$ ) performed visual and auditory tasks with and without unimodal and cross-modal distraction across five practice sessions. Reaction time decreased with practice in both age groups. Strikingly, this performance improvement was similar across the age groups. Moreover, distractor modality did not affect performance gains in either age group. Older adults were disproportionally affected by cross-modal visual distraction, however, corroborating previous studies. This age-related effect was mitigated during the practice sessions. Finally, there was no transfer of practice to neuropsychological test performance. These results suggest a high capacity of older individuals to improve selective attention functions within and across sensory modalities.
\end{abstract}

\section{Introduction}

The ability to selectively attend to relevant information- and to resist distraction- is required for almost all conscious cognitive operations. The cognitive mechanisms underlying selective attention are twofold: Relevant information needs to be enhanced while irrelevant information needs to be inhibited. While filtering the constant stream of information we are daily confronted with is a challenge for people of all ages, older people appear to be especially challenged by it (e.g., Gazzaley, Cooney, McEvoy, Knight, \& D'Esposito, 2005; Lustig, Hasher, \& Tonev, 2001). This notion has led to the so-called "inhibitory deficit hypothesis" (Hasher \& Zacks, 1988; Lustig, Hasher, \& Zacks, 2007), which claims that older adults are disproportionally affected by taskirrelevant information because of a reduced inhibitory function. While it was long implied that age-related distractibility is a universal phenomenon, recent investigations have suggested that it strongly depends on the sensory modality in which relevant and irrelevant information are presented (Guerreiro, Murphy, \& Van Gerven, 2010; Van Gerven \& Guerreiro, 2016). However, the exact pattern of age-related, sensoryspecific distractibility across visual and auditory attention and distraction is still a matter of debate. Summarizing research on age-related distractibility before 2010, a review by Guerreiro et al. (2010), has shown that older adults are most likely to be disproportionately affected when the distraction is presented through the same modality as the target (i.e., unimodal distraction). Moreover, it has been demonstrated that older adults are particularly impaired if the distraction is visual, rather than auditory (Guerreiro, Murphy, \& Van Gerven, 2013; Guerreiro \& Van Gerven, 2011). Using a visual or auditory working memory-based task with visual or auditory distraction, Guerreiro et al. (2013) showed that auditory attention with concurrent visual distraction is particularly affected in aging, echoing an earlier finding by Guerreiro and Van Gerven (2011), who specifically investigated crossmodal selective attention (see, however, Einstein, Earles, \& Collins, 2002; Guerreiro, Adam, \& Van Gerven, 2014). In contrast to earlier

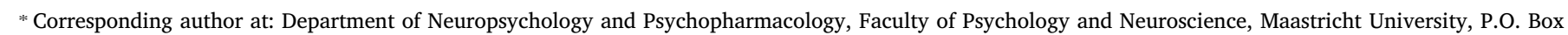
616, 6200 MD Maastricht, the Netherlands.

E-mail address: franziska.rienacker@maastrichtuniversity.nl (F. Rienäcker). 
findings (e.g., Guerreiro, 2010), more recent accounts have reliably demonstrated an intact ability of older individuals to selectively attend to information with concurrent distraction presented in the same modality (see, e.g., Leiva, Andres, \& Parmentier, 2015; Leiva, Parmentier, \& Andres, 2014).

A possible mechanism explaining why older, and not younger, individuals are impaired in their ability to discriminate between relevant and irrelevant cross-modal information, is an increased level of multisensory integration (Diederich, Colonius, \& Schomburg, 2008; Laurienti, Burdette, Maldjian, \& Wallace, 2006). Multisensory integration occurs when concurrent information from more than one modality is combined to facilitate further cognitive processing. It is hypothesized that this increased multisensory integration in older adults is the result of a broadened temporal binding window for integration, meaning a longer period in which consecutive stimuli from two modalities will be perceived as paired (Diederich et al., 2008; McGovern, Roudaia, Stapleton, McGinnity, \& Newell, 2014; Setti, Burke, Kenny, \& Newell, 2011). Older adults might employ multisensory integration to a larger degree to counteract age-related sensory decline. Although increased multisensory integration may support cognitive functioning in circumstances where congruent multisensory information is present, it could hamper performance if one stream of information is irrelevant and interferes with the processing of the relevant stream (Andrés, Parmentier, \& Escera, 2006).

An important, but not yet fully investigated issue is whether modality-specific selective attention deficits in older adults can be mitigated. While selective attention seems to become more and more important in today's information society, with increased emphasis on modern media, several studies have attempted to improve selective attention in older adults with video game training. For example, Belchior et al. (2013) were able to observe gains of performance in older adults (65-91 years) on the Useful Field Of View (UFOV) tasks involving unimodal visual distraction, achieved with help of training involving repeated exposure to standard video games for six sessions of 90 min each (e.g., Medal of Honor, Tetris). The capacity of older adults to improve selective attention with help of video game training was also demonstrated by Mayas, Parmentier, Andrés, and Ballesteros (2014). In this intervention, participants were asked to practice video games focused on improving cognitive capacities along a wide number of domains during 20 one-hour training sessions.

None of these training studies compared the ability of older adults to practice selective attention with that of younger individuals, so it remains to be seen whether the commonly observed age-related differences in distractibility can be fully mitigated. Li, Allen, Lien, and Yamamoto (2017) suggest that older and younger adults might benefit to similar degrees from practice (i.e., improve with similar learning rates and magnitudes) in the context of perceptual learning (mainly in the visual domain). While support for an equal ability to achieve practice gains across age groups comes also from a dual-task training (Allen, Lien, Ruthruff, \& Voss, 2014), it appeared from this study that older adults despite visible improvements, are far from reaching younger adults' baseline performance after repeated practice.

However, none of the previously mentioned studies investigated possible differences in reduction of distractibility specifically, and in more than one modality or target-distraction combination. Still, while selective attention decrements are common in healthy aging, they do not seem to be an all-encompassing phenomenon, but rather depend on sensory modality. So an important, but not yet fully investigated issue is whether modality-specific selective attention deficits in aging people can be mitigated. To our knowledge, only one study, conducted by Mozolic, Long, Morgan, Rawley-Payne, and Laurienti (2011), showed promising results using an extensive selective attention training program that included exercises encompassing all possible combinations of visual and auditory target and distractor stimuli. However, because this study only investigated training effects on visual selective attention, it remains unknown to what extent auditory selective attention is trainable in older adults. Furthermore, also Mozolic et al. did not include a healthy younger control group, so that the capacity of older adults to improve selective attention could not be directly compared to that of younger adults. Moreover, the pre-post measurement design did not enable them to explore performance improvement over the course of the 8-week training period. However, Mozolic et al. did demonstrated transfer of practice gains to untrained cognitive domains, such as cognitive processing speed and dual-task performance. This is striking, because transfer to untrained domains or everyday activities has rarely been demonstrated before in cognitive intervention programs for older adults (Reijnders, van Heugten, \& van Boxtel, 2013). Given these findings and the overarching role selective attention has on cognitive processing, investigating the capacity of older adults to achieve practice gains on selective attention performance is a promising research avenue. Because the complex training program designed by Mozolic et al. (2011) involved many different exercises in different settings, different materials, and different instructions, we aimed to investigate whether similar positive effects in older individuals can be achieved by only practicing a single task with high selective attention demands.

While in some studies practice effects are considered a confounding factor (e.g., Machulda et al., 2013), we and others consider the ability to achieve performance gains by repeated exposure to a cognitive task to be of primary interest (Claus, Mohr, \& Chase, 1991; Foley, Cocchini, Logie, \& Sala, 2015; Li et al., 2008). The so called "testing-the-limits" approach assigns special importance to practice in old age. According to this view, age-induced cognitive deficits can only be described adequately after a maximum performance potential, or "latent reserve capacity", has been reached through extensive practice (Lindenberger \& Baltes, 1995; Lindenberger, Kliegl, \& Baltes, 1992). Within this framework, it can be hypothesized that age-related, modality-specific selective attention deficits are attenuated after extensive practice, that is, after the latent reserve capacity of selective attention in older adults has been exploited.

As a secondary goal of our study, we aimed to investigate whether practice gains can transfer to other tasks and cognitive domains (cf. Mozolic et al., 2011). Among others, Li et al. (2008) not only reported performance gains in younger and older individuals after repeated exposure to a working memory task, but also transfer effects to similar memory tasks (i.e., near transfer). However, they did not find transfer to tasks tapping into other cognitive domains (i.e., far transfer).

In sum, the primary goals of the current study were to investigate (1) whether selective attention performance of younger and, especially, older adults improves after practice and whether the improvement across sessions is comparable across age groups, (2) whether our previous results of modality-dependent selective attention impairments (i.e., specifically affecting cross-modal auditory attention; Guerreiro et al., 2013) in older adults can be replicated, and (3) whether improvement by practice differs across modalities of attention and distraction. As a secondary goal, we aimed to investigate whether repeated exposure to high selective attention demands can positively influence performance in other cognitive domains, such as memory, executive functioning, and processing speed.

\section{Method}

\subsection{Participants}

Thirty-one younger $\quad(M=22.8$ years, $\quad S D=2.2$, range $=20-29$ years, $22.6 \%$ female) and 30 older participants $(M=70.4, S D=5.6$, range $=63-80$ years, $50.0 \%$ female $)$ participated in the current study. They were recruited via advertisements posted on local bulletin boards. None of the participants suffered from any psychiatric disorders (depression, anxiety disorder, etc.), neurological conditions (stroke, dementia, etc.), or other medical issues that could impact cognitive functioning. All participants had normal or correctedto-normal vision and hearing, and none of them were color-blind. 

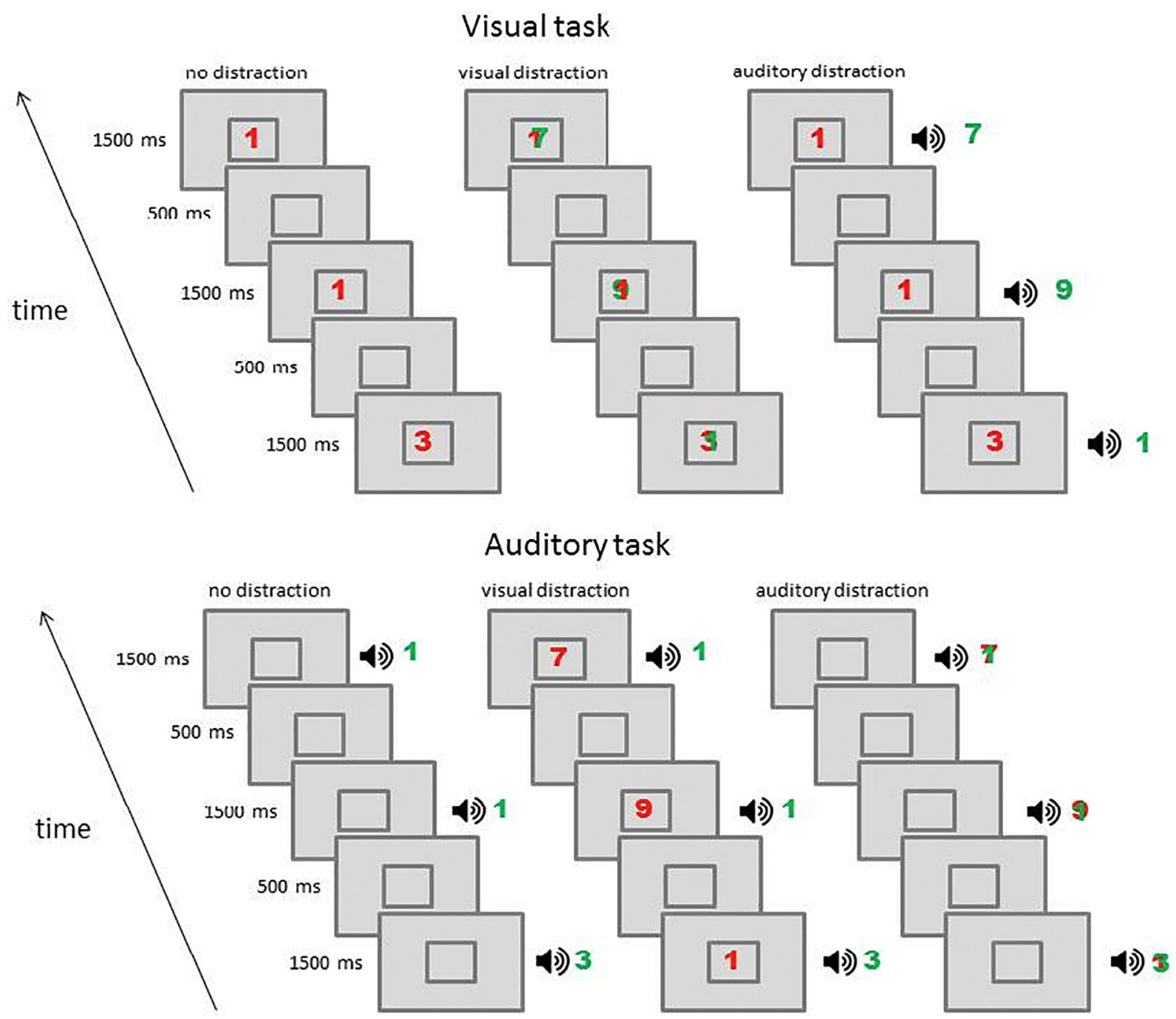

Fig. 1. Time course of the visual and auditory $n$-back tasks with no distraction, visual distraction, and auditory distraction.

Younger and older participants did not differ in the number of years of formal education, $t(14.88)=0.262, \quad p=.797 \quad(M=17.20$ years, $S D=1.32$ years, and $M=16.86$ years, $S D=4.74$ years, respectively). Data of one older participant were excluded from the analyses because he repeatedly looked away from the screen or closed his eyes to avoid visual distraction. Twenty-nine participants (16 younger, 13 older) were randomly assigned to the selective attention practice group and 31 participants (15 younger, 16 older) were assigned to the control group, which performed the same tasks without distraction (for a visualization of our experimental design, see Fig. 2).

The Montreal Cognitive Assessment (MOCA), a cognitive screening instrument consisting of small paper-and-pencil tasks across different cognitive domains (Nasreddine et al., 2005), was administered to check that all participants were cognitively normal, and to exclude the possibility of any form of pathological aging in the older sample (a score $>25$ is considered a normal outcome). Both younger and older participants performed within the normal range $(M=28.52$, $S D=1.44$, and $M=27.58, S D=1.30$, respectively). Only two participants obtained a borderline score of 25 points (one older and one younger participant). Given their good performance on all other neuropsychological tests, we concluded that this score was most likely not related to pathological cognitive decline. Analyses with and without these two cases did not lead to different outcomes.

This study was approved by the Ethics Review Committee Psychology and Neuroscience of Maastricht University (protocol no.
ECP-156 0109 2015). All participants gave written informed consent before their participation.

\subsection{Tasks and stimuli}

The primary outcome measures were visual and auditory $n$-back task performance with and without distraction. The tasks were programmed in E-Prime, version 22 (Psychology Software Tools, Pittsburgh, PA). Previous work from our lab has demonstrated that agerelated differences in distractibility are detectable with this task (Guerreiro et al., 2013; Guerreiro \& Van Gerven, 2011). By using the same paradigm, we hoped to achieve some degree of comparability and extend existing results by adding a multiple-session training. While we did not expect differences in distractibility across memory-load conditions (1-back, 2-back) per se, we included both task types to ensure that effects of repeated practice and/or distraction could not be missed because of the tasks being either too easy or too difficult. Secondary outcome measures were neuropsychological test scores including the Verbal Learning Test, the Stroop Color-Word Test, the Concept Shifting Test, and the Letter-Digit Substitution Test). We also measured both vision and hearing abilities to check whether sensory acuity affected the impact of distraction on the participants' performance.

\subsubsection{Visual and auditory $n$-back tasks}

We employed visual and auditory n-back tasks, which have shown 
robust age effects in our previous work (Guerreiro et al., 2013). In these computer tasks, participants were presented with a random stream of digits, ranging from 1 to 9 , which were presented one at a time. For each digit after the $n$ th, participants were required to indicate if it matches the one $n$ position back in the sequence. Every condition extended over $n+64$ digits. Two memory load conditions were included ( $n=1$ and $n=2$ ). During the primary visual task, digits were presented in the colors red or green. Stimuli were approximately $2.7 \times 3.6 \mathrm{~cm}$ and were presented on a 17-in. computer screen. Auditory stimuli were presented through Sennheiser HD 280 stereo headphones. The spoken digits were recorded by a male or a female speaker at a sampling rate of $22 \mathrm{kHz}$ and 16-bit resolution. For all participants, spoken numbers were presented at an average sound level of $75 \mathrm{~dB}$. All stimuli were presented for $500 \mathrm{~ms}$, with an inter-stimulus interval of $1500 \mathrm{~ms}$. The task was self-paced, that is, the stimulus presentation was terminated and followed by the next trial as soon as a response was given. Responses were given by means of a button box on which two buttons were labeled "YES" (the digits do match) and "NO" (the digits do not match). The participants were instructed to "respond as quickly and accurately as possible". After each condition, participants were presented with the number of correct responses they had given. No further instruction, feedback, or advice was provided. Level of performance was determined by the speed (reaction time in ms) and accuracy, across the 64 trials of a task condition. We expected reaction time scores to be more reliable and informative, as accuracy scores of $n$-back tasks are often vulnerable to ceiling effects, especially in healthy young participants (Barth, Strehl, Fallgatter, \& Ehlis, 2016; Jaeggi, Buschkuehl, Perrig, \& Meier, 2010).

\subsubsection{Visual and auditory distraction}

Auditory and visual 1- and 2-back tasks were each administered without distraction, with visual distraction, and with auditory distraction (Fig. 1). Visual distractors were random red or green digits between 1 and 9. Participants were told their gaze would be watched carefully by the experimenter, in order to ensure they did not look away or close their eyes to avoid visual distraction. Auditory distraction consisted of random spoken numbers in the same range (1-9). In the unimodal visual distraction condition, numbers of the opposite color (green or red) were superimposed on the target stimuli. In the unimodal auditory distraction condition, target numbers were uttered by a speaker of the opposite sex, and presented $5 \mathrm{~dB}$ louder than the distractors. Thus, in the unimodal conditions, target and distractor stimuli were presented concurrently and perceptually overlapping.

Previous work has demonstrated that the ability to perceive stimuli in these conditions is not disrupted and that both younger and older individuals are still able to perceive the masked target stimuli (Guerreiro et al., 2013). Target-distractor identification was counterbalanced such that half of the participants were instructed to attend to red and female-spoken stimuli, whereas the other half were instructed to attend to green and male-spoken numbers.

\subsubsection{Neuropsychological test battery}

Four standard neuropsychological tests were used to investigate transfer effects of selective attention practice to other cognitive domains.

The Verbal Learning Test (VLT) was used to assess encoding and retrieval functions of verbal episodic memory, as well as learning capacity (Van der Elst, Van Boxtel, Van Breukelen, \& Jolles, 2005). This test required participants to listen to a series of fifteen words, after which they were asked to immediately repeat as many of these words as possible. This was repeated five times consecutively using the same fifteen words. After a period of $20 \mathrm{~min}$, a delayed free recall and a recognition test were administered. Test scores were determined by the number of words they were able to recall or recognize correctly.

The Stroop Color-Word Test (SCWT) was administered to measure cognitive flexibility, executive control, and the ability to inhibit a habituated response (Uttl \& Graf, 1997). The task included three charts each of which contained 100 color stimuli. The first chart showed color words, written in black ink, and the participant's task was to read them out loud as quickly as possible. On the second chart, colored bars were presented, the colors of which had to be named, again as quickly as possible. The third chart contained written color words, the ink color of which was incongruent with those color words (e.g., the color word "green" printed in red ink). In this subtask, participants were required to name the color of the ink of each word and not to read aloud the color word. The interference score was calculated by subtracting the average time required to complete the first two charts from the time required to complete the third chart (Stroop, 1935; Van der Elst, Van Boxtel, Van Breukelen, \& Jolles, 2006).

The Concept Shifting Test (CST) is a measure of cognitive flexibility. In this test, circles containing letters, digits, or both, were arranged in three bigger circles on three different sheets. On the first sheet, the circles included numbers (1-16) in random order and participants were asked to cross out each one in ascending order. On the second sheet, letters (A-P) were presented, which had to be crossed out in alphabetic order. On the third and last sheet, both numbers (1-8) and letters (A-H) were displayed in random order. The participant's task was to cross out letters and digits in an alternate fashion (1, A, 2, B, 3, C, etc.), in ascending order and as quickly as possible. Outcome variable was the time (seconds) needed to complete the tasks. The additional time needed to complete the third tasks as compared to the first two is considered to reflect concept shifting time, a measure of cognitive flexibility (concept shifting time $=$ time on sheet $3-$ [time on sheet $1+$ time on sheet 2] / 2) (Vink \& Jolles, 1985).

The Letter-Digit Substitution Test (LDST) was employed as a primary measure of processing speed, sustained attention, visual scanning abilities, and psychomotor speed (Van der Elst et al., 2006). In this paper-and-pencil test, participants were asked to translate, as quickly as possible, an array of digits into pre-specified symbols. A key to the right combinations was given at the top of the page. Participants received a score corresponding to the number of digits they were able to translate in $2 \mathrm{~min}$.

\subsubsection{Visual and auditory acuity}

Visual acuity was measured by means of the Dutch Radner Reading charts (Maaijwee, Meulendijks, Radner, van Meurs, \& Hoyng, 2007; Maaijwee, Mulder, Radner, \& Van Meurs, 2008). This instrument presents participants with letters in different font sizes. The score is determined by the smallest font size the participant can read in $20 \mathrm{~s}$ and with less than three reading errors.

Auditory acuity testing was done using a screening audiometer, measuring pure-tone thresholds in each ear at 1, 2, and $4 \mathrm{kHz}$. Hearing acuity was determined as the average hearing threshold (in $\mathrm{dB}$ ), for the best ear, averaged across the three frequencies (Davis, 1995).

\subsection{Procedure}

All participants were invited to the lab for five consecutive test sessions. Sessions were planned at least two and maximally four days apart. Participants from both age groups were randomly divided into a selective attention practice group $(n=30,16$ younger, 14 older participants) or a control group ( $n=31,15$ younger, 16 older participants). In each session, practice group participants performed one run of each of the twelve $n$-back conditions with and without distraction as described above. Control participants performed the same number of 1and 2-back tasks, but all without distraction. During the first session, before the first exposure to the n-back tasks, the sensory acuity tests, and the neuropsychological test battery were administered to all participants (see Fig. 2 for an overview). Parallel versions of the neuropsychological tasks and the MSI task were used after the fifth and last session of $n$-back tasks. Breaks were offered in between at each participant's convenience. Following their participation, participants 


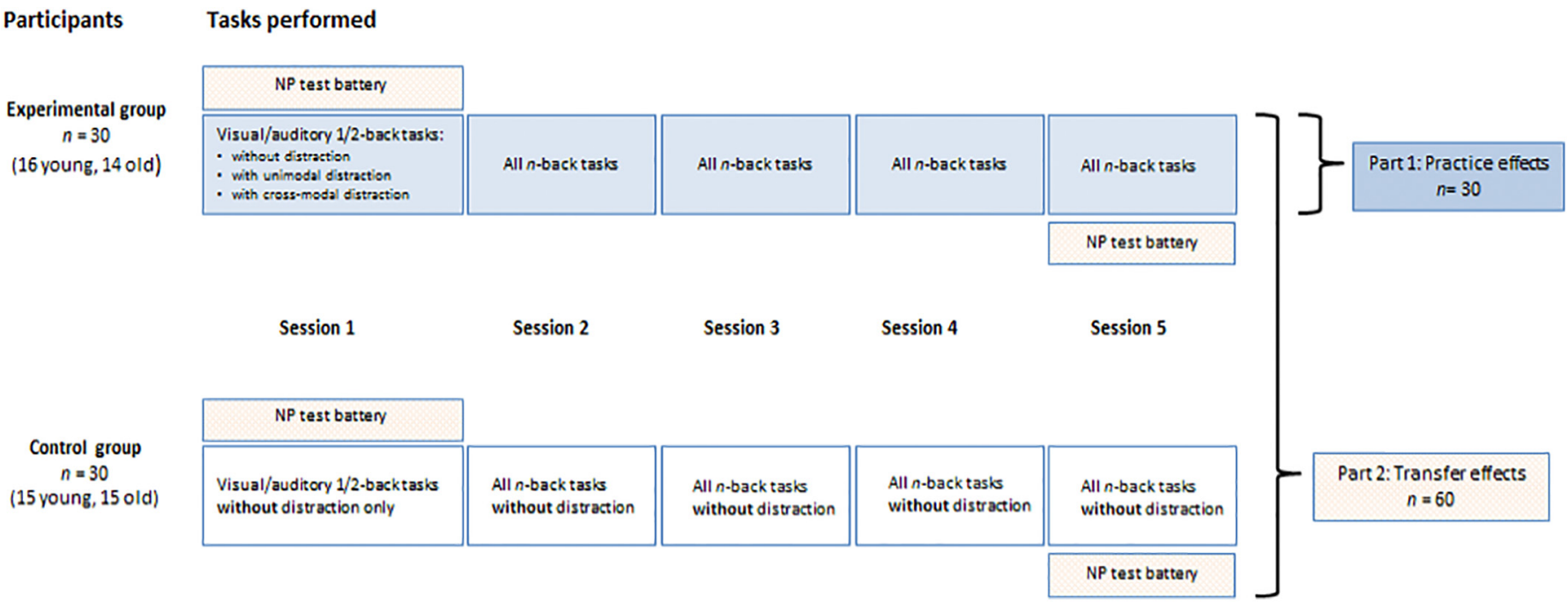

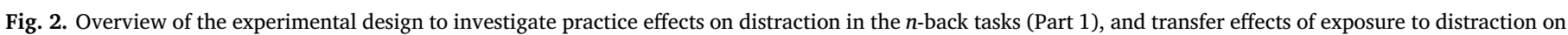
NP performance (Part 2).

received a financial compensation of $€ 7.50$ per hour, plus a reimbursement of possible transportation costs.

\subsection{Statistical analyses}

All statistical analyses were performed with IBM SPSS Statistics version 22. All outcomes were considered significant at $p<.05$. A Greenhouse-Geisser correction was applied when the assumption of sphericity was violated (Collier, Baker, Mandeville, \& Hayes, 1967). As reaction times (averaged over sessions and distraction and memory load conditions) were normally distributed for both age groups (as indicated by insignificant Shapiro-Wilk statistics: $p=.642$ and $p=.226$ for younger and older participants, respectively) we refrained from applying logarithmic transformation. Bonferroni correction was applied to account for multiple testing across different levels of each factor.

To assess the effects of selective attention practice across sessions, effects of uni- and cross-modal distraction, and their interaction with age group, reaction times (RT) and accuracy of the 30 practice group cases were analyzed per task (visual or auditory $n$-back task) and level of memory load (1-back or 2-back), using a 2 (Age Group: young or old) $\times 3$ (Distraction: no distraction, unimodal distraction, and crossmodal distraction) $\times 5$ (Practice Session: 1-5) mixed repeated-measures analysis of variance (ANOVA). Age Group was the betweengroups factor; Distraction and Session were the within-groups factors.

To assess possible group-specific pre- to post-practice effects on neuropsychological performance, test performance on all tests were analyzed with a 2 (Practice Group: selective attention practice or control) $\times 2$ (Age Group: young or old) $\times 2$ (Test Session: pre- or postpractice) repeated measures ANOVA.

We performed a post-hoc power analysis using $G^{*}$ Power 3.0.10 (Faul, Erdfelder, Lang, \& Buchner, 2007) with a total sample size of 30 and a medium effect size $(f=0.25)$ for the performed $F$ tests (repeatedmeasures ANOVA with five levels, two groups, and within-between interaction), which resulted in an estimated power of 0.94 .

\section{Results}

\subsection{Reaction time}

All analyses on reaction times are based on averaged values across correct responses per participant and per condition.

\subsubsection{Visual 1-back task}

There was a main effect of Age Group, $F(1,28)=83.46, p<.001$, $\eta_{\mathrm{p}}{ }^{2}=0.75$, indicating that younger adults responded faster than older adults $(M=419 \mathrm{~ms}, S D=74$, and $M=599, S D=79$, respectively). Furthermore, there was a main effect of Practice Session, $F(2.04$, 57.03) $=35.96, p<.001, \eta_{\mathrm{p}}{ }^{2}=0.56$. Pairwise comparisons revealed a decrease in reaction times from session 1 to $2(p<.001), 2$ to 3 $(p<.001), 2$ to $4(p=.035)$ and 3 to $5(p<.001)$, but not from 3 to 4 $(p=.319)$ and 4 to $5(p=.114)$. See Table 1 for means and standard deviations. There was no interaction between Age group and Practice session, $F(4,57.03)=0.53, p=.100$. Distraction significantly influenced RTs, $F(2,36)=42.06, p<.001, \eta_{\mathrm{p}}{ }^{2}=0.60$, such that unimodal (visual) distraction resulted in significantly slower responses compared to no distraction, $p<.001(M=558 \mathrm{~ms}, S D=79$, and $M=486 \mathrm{~ms}$, $S D=49$, respectively). Cross-modal auditory distraction did not influence performance compared to no distraction, $p=.592(M=483 \mathrm{~ms}$, $S D=10)$. There was no significant interaction between Distraction and Age Group, $F(1.29,36)=1.79, p=.176$, or Distraction and Practice Session $(F<1)$. The three-way Practice Session $\times$ Distraction $\times$ Age Group interaction was also non-significant $(F<1)$.

\subsubsection{Visual 2-back task}

A similar pattern of results was observed for the higher memory load (2-back) conditions. There was an effect of Age Group, $F(1$, $28)=81.22, p<.001, \eta_{\mathrm{p}}{ }^{2}=0.74$. Overall, younger adults responded significantly faster than older adults $(M=485, S D=99$, and $M=724$, $S D=101$, respectively). Furthermore, there was a main effect of Practice Session, $F(2.34,65.42)=86.92, p<.001, \quad \eta_{\mathrm{p}}{ }^{2}=0.76$. Pairwise comparisons revealed a decrease in reaction times from session 1 to 2 ( $p<.001), 2$ to $3(p<.001), 2$ to $4(p<.001)$ and 4 to 5 $(p=.020)$, but not between sessions 3 and $4(p=.059)$. Means and standard errors are plotted in Fig. 3. There was no interaction between

Table 1

Visual 1-back task: mean reaction times and standard devisations in the five practice sessions.

\begin{tabular}{clllll}
\hline & $\begin{array}{l}\text { Session 1 } \\
M(S D)\end{array}$ & $\begin{array}{l}\text { Session 2 } \\
M(S D)\end{array}$ & $\begin{array}{l}\text { Session 3 } \\
M(S D)\end{array}$ & $\begin{array}{l}\text { Session 4 } \\
M(S D)\end{array}$ & $\begin{array}{l}\text { Session 5 } \\
M(S D)\end{array}$ \\
\hline $\begin{array}{c}\text { Younger } \\
(n=16)\end{array}$ & 491 & 433 & 401 & 400 & 369 \\
$\begin{array}{c}\text { Older } \\
(68)\end{array}$ & 683 & $(48)$ & $(40)$ & $(92)$ & $(32)$ \\
& 606 & 589 & 564 & 555 \\
& $(82)$ & $(64)$ & $(75)$ & $(79)$ & $(67)$
\end{tabular}




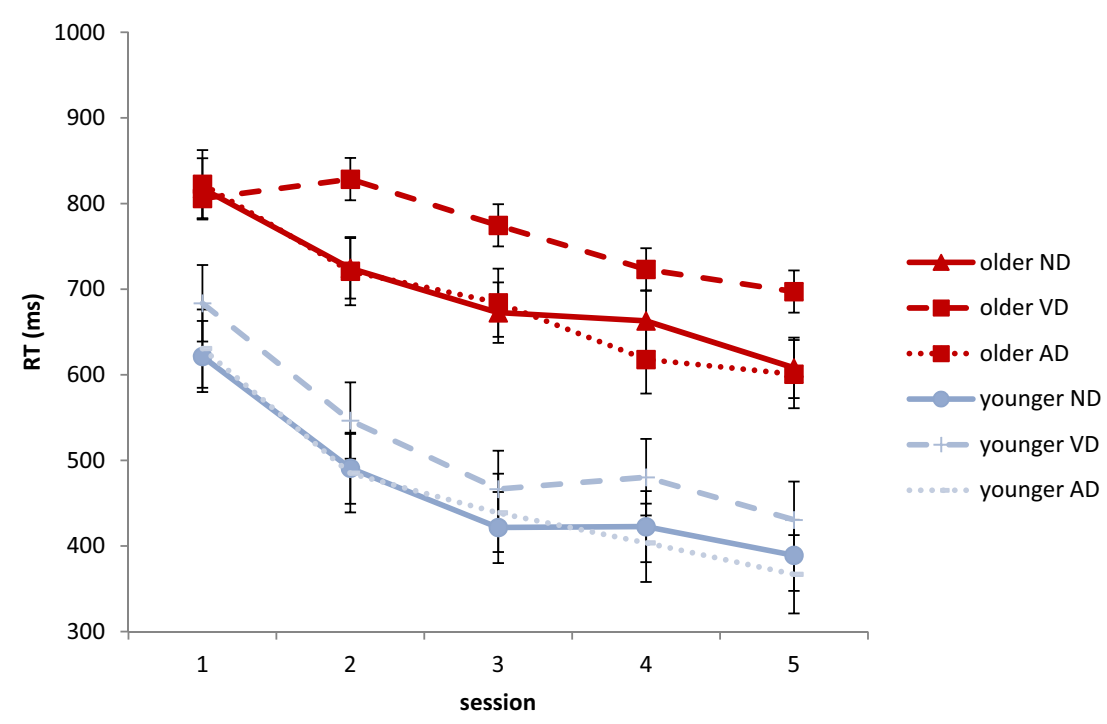

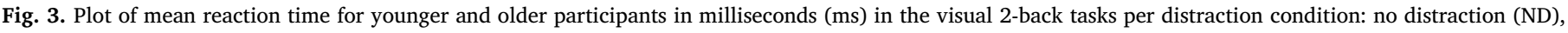
visual distraction (VD), and auditory distraction (AD). Error bars indicate one standard error of the mean.

Age Group and Practice Session, $F(2.34,65.42)=1.52, p=.224$. Distraction significantly influenced RTs on the visual 2-back tasks, $F(1.51$, $42.14)=31.64, p<.001, \eta_{\mathrm{p}}{ }^{2}=0.53$, such that unimodal (visual) distraction resulted in significantly slower responses compared to no distraction, $p<.001, M=654 \mathrm{~ms}, S D=87$, and $M=583 \mathrm{~ms}$, $S D=71$, respectively. Cross-modal auditory distraction did not influence performance compared to no distraction, $p=.466, M=577 \mathrm{~ms}$, $S D=82$. There was no significant interaction between Distraction and Age Group, $F(1.51,42.14)=2.13, p=.142$, or Distraction and Practice Session $(F<1)$. The three-way Practice Session $\times$ Distraction $\times$ Age Group interaction was also non-significant $(F<1)$.

\subsubsection{Auditory 1-back task}

There was an effect of Age Group, $F(1,28)=37.60, p<.001$, $\eta_{\mathrm{p}}{ }^{2}=0.57$. Overall, younger adults responded significantly faster than older adults $(M=569, S D=102$, and $M=736, S D=109$, respectively). Furthermore, there was a main effect of Practice Session, $F$ $(1.92,53.83)=60.03, p<.001, \eta_{\mathrm{p}}{ }^{2}=0.68$. Pairwise comparisons revealed a decrease in reaction time from session 1 to $2(p<.001), 2$ to $3(p<.001), 3$ to $4(p<.001)$, and 4 to $5(p<.001)$. See Table 2 for means and standard deviations.

There was no interaction between Age Group and Practice Session, $F$ $(1.92,53.83)=1.04, p=.410$. The interaction between Age Group and distraction was significant, $F(1.82, \quad 51.07)=5.49, \quad p=.007$, $\eta_{\mathrm{p}}{ }^{2}=0.16$, indicating that younger adults were significantly distracted by unimodal auditory distraction $(p<.001)$, but not by cross-modal visual distraction $(p=.153)$, whereas older adults responded significantly slower in both distraction conditions, as compared to no distraction, $p<.001$ and $p=.024$ (Fig. 4). No interaction between Distraction and Practice Session was observed $(F>1)$. The three-way Practice Session $\times$ Distraction $\times$ Age Group interaction was also nonsignificant $(F>1)$.

Table 2

Auditory 1-back task: mean reaction times and standard deviations in the five practice sessions.

\begin{tabular}{clllll}
\hline & $\begin{array}{l}\text { Session 1 } \\
M(S D)\end{array}$ & $\begin{array}{l}\text { Session 2 } \\
M(S D)\end{array}$ & $\begin{array}{l}\text { Session 3 } \\
M(S D)\end{array}$ & $\begin{array}{l}\text { Session 4 } \\
M(S D)\end{array}$ & $\begin{array}{l}\text { Session 5 } \\
\text { M }(S D)\end{array}$ \\
\hline $\begin{array}{c}\text { Younger } \\
\quad(n=16)\end{array}$ & 668 & 600 & 551 & 524 & 499 \\
Older & $(116)$ & $(100)$ & $(83)$ & $(80)$ & $(72)$ \\
$\quad(n=14)$ & $(71)$ & 765 & 733 & 714 & 692 \\
& $(13.63)$ & $(52)$ & $(67)$ & $(77)$ \\
\hline
\end{tabular}

\subsubsection{Auditory 2-back task}

There was an effect of Age Group, $F(1,28)=38.52, p<.001$, $\eta_{\mathrm{p}}{ }^{2}=0.58$. Overall, younger adults responded significantly faster than older adults $(M=604 \mathrm{~ms}, S D=141$, and $M=838 \mathrm{~ms}, S D=151$, respectively). Furthermore, there was a significant interaction between Age Group and Practice Session, $F(1.77,49.58)=6.08, p=.006$, $\eta_{\mathrm{p}}{ }^{2}=0.18$. Younger adults improved faster across sessions than older adults (see Fig. 4). Even though younger participants' RTs decreased across all sessions (between 1 and $2, p<.001 ; 2$ and $3, p<.001 ; 3$ and $4, p<.001 ; 4$ and $5, p=.005)$, older participants only improved between session 1 and $3(p=.005), 2$ and $3(p=.005)$, and 3 and 5 $(p<.001)$, not between session 1 and $2(p=.140)$ and 3 and 4 $(p=.075)$. Means and standard errors are plotted in Fig. 5. Distraction significantly influenced RTs in the auditory 2-back tasks, $F(2$, $56)=18.30, p<.001, \eta_{\mathrm{p}}{ }^{2}=0.40$, such that unimodal auditory distraction resulted in significantly slower responses compared to no distraction, $p<.001(M=747 \mathrm{~ms}, \quad S D=105, \quad$ and $M=706 \mathrm{~ms}$, $S D=112$, respectively). Cross-modal visual distraction did not influence performance as compared to no distraction, $p>.100$ ( $M=709.38 \mathrm{~ms}, S D=100.29)$. No interaction between Distraction and Age Group $(F<1)$, or Distraction and Practice Session was observed, $F$ $(4.03,112.82)=1.44, p>.224$. The three-way Practice Session $\times$ Distraction $\times$ Age Group interaction was also non-significant, $F$ $(4.03,112.82)=2.01, p=.098$.

\subsection{Accuracy}

Accuracy scores of the younger participants showed clear ceiling effects and little variability across all task conditions, ranging from a group mean of $58.40(S D=21.25)$ to 62.38 ( $S D=7.94)$ correct responses out of a maximum score of 64 per condition. For this reason, we refrained from analyzing or interpreting the accuracy data from the younger subsample.

For the older participants, there was a Practice Session effect for all four primary tasks (see Table 3), showing improved performance across sessions, which suggests that the previously demonstrated reaction time gains did not come at the cost of reduced accuracies.

Distraction did not affect accuracy in the visual 1- and 2-back task $(F s<1)$, and in the auditory 1-back task, $F(1.40,19.87)=2.41$, $p=.185$. Distraction did, however, significantly affect accuracy of auditory 2-back task performance, $F(2,13)=11.41, p<.001$, $\eta_{\mathrm{p}}{ }^{2}=0.47$. Overall, cross-modal visual distraction resulted in 


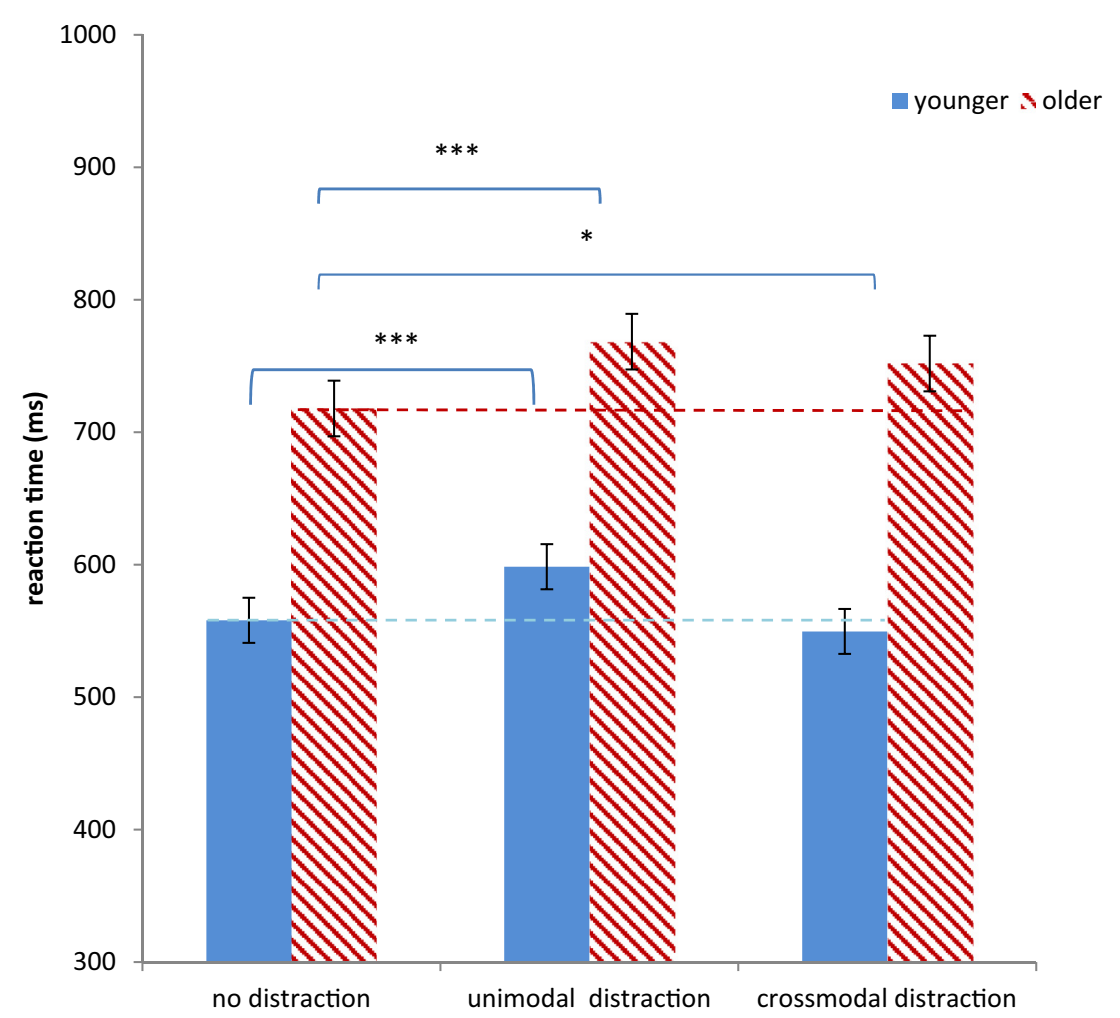

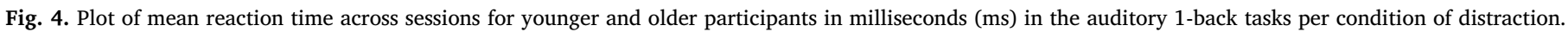
Error bars indicate one standard error of the mean. ${ }^{*} p<.05 .{ }^{*} p<.01 .{ }^{*} *{ }^{*} p<.001$.

significantly fewer accurate responses compared to no distraction, $p=.004(M=52.90, S D=12.00$, and $M=56.81, S D=9.26$, respectively). This is indicative of difficulties older people have with this specific cross-modal target-distractor combination. Unimodal auditory distraction did not influence performance as compared to no distraction $(p=.677, M=55.43, S D=9.86)$. Furthermore, an interaction between Distraction and Practice Session was observed, $F(3.93$, $51.06)=3.05, p=.026, \eta_{\mathrm{p}}{ }^{2}=0.19$, indicating that in this sample of older participants, the negative effects of cross-modal distraction were attenuated after repeated practice of the distraction tasks (see Fig. 6).
Paired samples $t$-tests revealed significant differences between no distraction and visual distraction only in session $1, t(13)=3.36, p=.005$, and session $2, t(13)=3.33, p=.005$, but there were no differences in session $3, t(13)=2.03, p=.064$, session $4(t<1)$, and session 5 $(t<1)$.

\subsection{Transfer of practice effects}

\subsubsection{Neuropsychological performance}

The total number of words recalled during the Verbal Learning Test

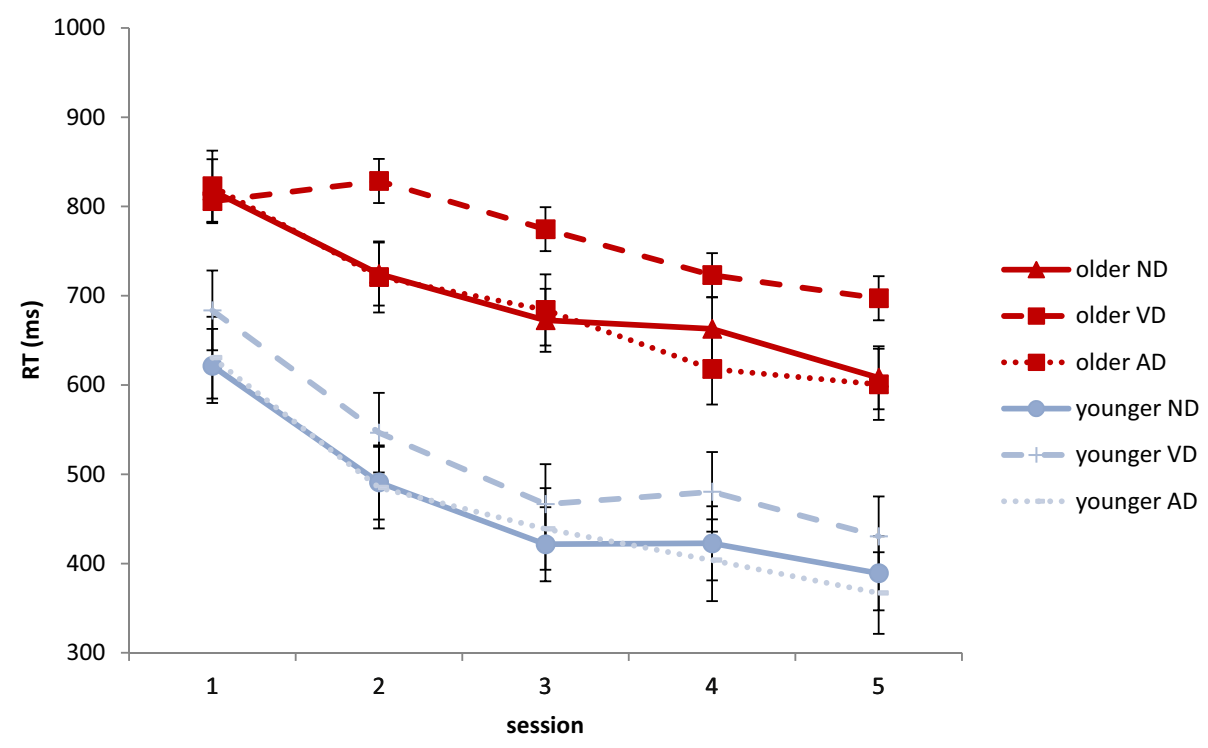

Fig. 5. Plot of mean reaction time for younger and older participants in milliseconds (ms) in the auditory 2-back tasks per distraction condition: no distraction (ND), visual distraction (VD), and auditory distraction (AD). Error bars indicate one standard error of the mean. 
Table 3

Mean accuracy scores and standard deviations per session of the older participants.

\begin{tabular}{|c|c|c|c|c|c|c|}
\hline Task & $\begin{array}{l}F(\mathrm{df}) \\
p\end{array}$ & $\begin{array}{l}\text { Session } 1 \\
M(S D)\end{array}$ & $\begin{array}{l}\text { Session } 2 \\
M(S D)\end{array}$ & $\begin{array}{l}\text { Session } 3 \\
M(S D)\end{array}$ & $\begin{array}{l}\text { Session } 4 \\
M(S D)\end{array}$ & $\begin{array}{l}\text { Session } 5 \\
M(S D)\end{array}$ \\
\hline Visual 1-back & $\begin{array}{l}3.73(1.69,24.94) \\
.040\end{array}$ & $\begin{array}{l}59.54 \\
(4.83)\end{array}$ & $\begin{array}{l}61.07 \\
(3.67)\end{array}$ & $\begin{array}{l}61.76 \\
(1.42)\end{array}$ & $\begin{array}{l}61.95 \\
(1.98)\end{array}$ & $\begin{array}{l}61.86 \\
(1.98)\end{array}$ \\
\hline Visual 2-back & $\begin{array}{l}24.91(2.10,32.80) \\
.000\end{array}$ & $\begin{array}{l}46.60 \\
(8.08)\end{array}$ & $\begin{array}{l}53.71 \\
(6.70)\end{array}$ & $\begin{array}{l}57.55 \\
(4.45)\end{array}$ & $\begin{array}{l}57.74 \\
(4.23)\end{array}$ & $\begin{array}{l}58.55 \\
(4.34)\end{array}$ \\
\hline Auditory 1-back & $\begin{array}{l}4.98(1.41,18.37) \\
.028\end{array}$ & $\begin{array}{l}56.24 \\
(10.03)\end{array}$ & $\begin{array}{l}59.79 \\
(4.98)\end{array}$ & $\begin{array}{l}60.74 \\
(3.89)\end{array}$ & $\begin{array}{l}61.60 \\
(2.51)\end{array}$ & $\begin{array}{l}61.77 \\
(2.02)\end{array}$ \\
\hline Auditory 2-back & $\begin{array}{l}12.73(1.23,15.93) \\
.002\end{array}$ & $\begin{array}{l}45.98 \\
(4.09)\end{array}$ & $\begin{array}{l}53.50 \\
(7.71)\end{array}$ & $\begin{array}{l}57.41 \\
(5.73)\end{array}$ & $\begin{array}{l}59.00 \\
(4.86)\end{array}$ & $\begin{array}{l}59.36 \\
(4.86)\end{array}$ \\
\hline
\end{tabular}

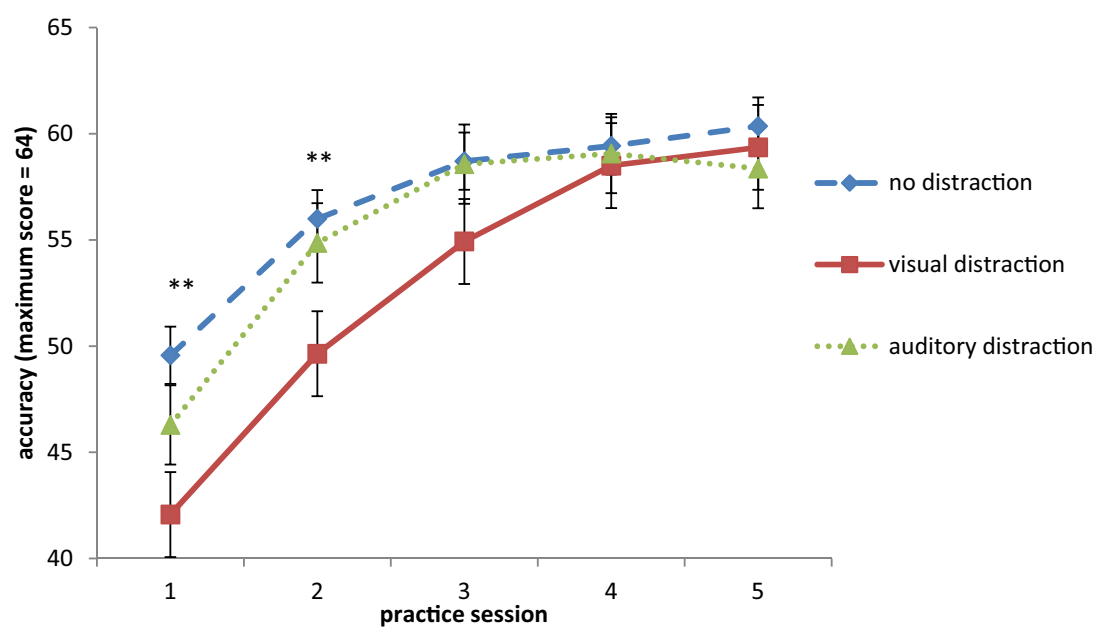

Fig. 6. Plot of mean accuracy scores out of 64 possible correctly matched numbers, and standard errors by practice session for the sample of older participants, and for no distraction, visual distraction, and auditory distraction conditions of the auditory 2-back task. Error bars indicate one standard error of the mean. Asterisks indicate significance for the comparisons between no distraction and visual distraction. ${ }^{*} p<.05 .{ }^{* *} p<.01 .{ }^{* * *} p<.001$.

was significantly influenced by Age Group, $F(1,54)=40.30, p<.001$, $\eta_{\mathrm{p}}{ }^{2}=0.43$. Overall, younger individuals recalled significantly more words than older individuals $(M=56.78$ words, $S D=12.55$, and $M=41.75$ words, $S D=13.40$, respectively). There was an effect of Test Session, $F(1,54)=8.34, p=.006, \eta_{\mathrm{p}}{ }^{2}=0.13$, but no interaction between Test Session and Age Group $(F<1)$, or Test Session and Practice Group $(F<1)$, indicating that all participants benefitted from the repeated practice $(M=47.93$ words, $S D=10.15$, and $M=50.60$ words, $S D=9.53$, respectively), but that this improvement did not depend on age or Practice Group.

Stroop interference scores differed between the age groups, as evident by a significant main effect of age-group, $F(1,54)=60.86$, $p<.001, \eta_{\mathrm{p}}{ }^{2}=0.56$. Overall, younger individuals displayed less Stroop interference than older individuals $(M=25.57 \mathrm{~s}, S D=17.12$, and $M=50.82 \mathrm{~s}, S D=18.36$, respectively). Interference was, however, not influenced by Practice Group, $F(1,54)=3.88, p=.054$.

Set shifting, as assessed by means of the CST differed between age groups, $F(1,54)=5.95, p=.018, \eta_{\mathrm{p}}{ }^{2}=0.11$, but was not influenced by Test Session $(F<1)$. Set shifting costs were on average $5.41 \mathrm{~s}$ $(S D=7.98)$ for younger-, and on average $9.07 \mathrm{~s}(S D=8.52)$ for older adults.

Processing speed was significantly influenced by Age Group $F(1$, $54)=46.59, p<.001, \eta_{\mathrm{p}}{ }^{2}=0.46$. Overall, younger adults could reproduce more letter-digit combinations than older individuals ( $M=87.69$ digits, $S D=21.07$, and $M=60.61, S D=22.46$, respectively). There was a main effect of Test Session, $F(1,54)=4.79$, $p=.033, \eta_{\mathrm{p}}{ }^{2}=0.08$, but no interaction between Test Session and Age Group, $F(1,54)=1.86, p>.352$, or Test Session and Practice Group $(F<1)$, indicating that, overall, participants increased digit reproduction from pre- to post-practice $(M=72.52$ digits, $S D=14.41$, and $M=75.78$ digits, $S E=18.20$, respectively), but that this improvement did neither depend on age, nor on Practice Group.

\subsection{Sensory acuity}

Visual acuity differed significantly across age groups, $t(28)=5.89$, $p<.001$. The mean score on the reading chart for younger participants was 0.78 (with a maximum score of 1.00 , indicating 20:20 vision) $(S D=0.13)$, for old participants it was $0.53(S D=0.10)$. To rule out that these differences influenced age differences in cross-modal visual distraction, zero-order Pearson correlations were calculated between visual acuity and cross-modal visual distraction per age group. Visual distraction was determined by subtracting reaction times in the auditory no-distraction conditions from those in the cross-modal visual distraction conditions for each participant and collapsed across memory load conditions. Visual acuity did neither correlate with visual distraction in the younger group, $r=-0.28, p=.289$, nor in the older group, $r=-0.16, p=.581$, which suggests that older adults' heightened susceptibility to cross-modal auditory distraction is independent of visual acuity. Additionally, visual acuity did not correlate with crossmodal auditory distraction, determined by subtracting reaction times in the visual no-distraction conditions from those in the cross-modal auditory distraction conditions for each participant and collapsed across memory load conditions, $r=0.13, p=.628$ in younger participants, and $r=-0.25, p=.392$ in older participants. This suggests that visual acuity differences had no influence on the susceptibility to cross-modal visual attention.

Hearing acuity also differed significantly across age groups, $t$ $(27)=-6.09, p<.001$. The mean hearing threshold for younger participants was $2.92 \mathrm{~dB}(S D=4.15)$, whereas for old participants it was $22.05 \mathrm{~dB}(S D=11.73)$, which can be regarded as a normal pattern of age-related hearing loss (Fozard \& Gordon-Salant, 2001). To rule out that these differences account for the observed lack of age differences in cross-modal auditory distraction, zero-order Pearson correlations were calculated between hearing thresholds and cross-modal auditory distraction. Hearing acuity did neither correlate with auditory distraction 
in the younger group, $r=-0.02, p=.935$, nor in the older group, $r=-0.19, p=.545$, which suggests that older adults' resistance to cross-modal auditory distraction is independent of auditory acuity. Additionally, auditory acuity did not correlate with cross-modal visual distraction in neither younger participants, $r=-0.33, p=.213$, nor in older participants, $r=-0.24, p=.438$. This suggests that older adult's heightened susceptibility to cross-modal visual distraction is not a result of a lowered auditory acuity (Guerreiro \& Van Gerven, 2017).

\section{Discussion}

The primary goals of the present study were to investigate the possibility to improve selective attention performance in older individuals through repeated practice and to determine whether practice effects are modulated by sensory modality. As expected, a consistent positive effect of practice of selective attention tasks could be documented in both age groups. This finding is in line with previous research showing practice effects in younger adults (e.g., Bartels, Wegrzyn, Wiedl, Ackermann, \& Ehrenreich, 2010; Collie, Maruff, Darby, \& McStephen, 2003).

What is striking in our results is that performance gains from practice do not differ between younger and older adults. While older adults consistently displayed longer reaction times than their younger counterparts, their ability to improve on these tasks seemed to be hardly impaired. On three of the four primary selective attention tasks (i.e., visual 1-back, visual 2-back, and auditory 1-back), we found no interaction between practice session and age group, indicating that the improvement across sessions was the same for younger and older adults during almost all task conditions. Only in the auditory 2-back task, the older participants showed a somewhat slower learning trajectory than the younger participants, as indicated by less and smaller performance increments across sessions. Importantly, overall the older adults were able to reach the younger adults' baseline level of performance, and to respond equally fast after four to five practice sessions, depending on the primary task. This has not been demonstrated in a range of other cognitive training studies (Allen et al., 2014; Maquestiaux, LaguëBeauvais, Ruthruff, Hartley, \& Bherer, 2010), where learning was either substantially slower, or baseline performance of the younger comparison groups could not be approached after practice. Although comparable research in the domain of selective attention is lacking, a high practice capacity that is unaffected by the normal aging process has been demonstrated previously for dual-task performance (Strobach, Frensch, Müller, \& Schubert, 2012). In this study, older and younger participants demonstrated equal performance gains across eight consecutive practice sessions.

The current study adds important evidence to the notion that older individuals have a high practice capacity, and extends these findings into the domain of selective attention, a cognitive function that is particularly affected by the aging process (Gazzaley et al., 2005; Lustig et al., 2007). The extent to which younger and older adults were able to achieve these practice gains is notable. While gains are most commonly observed during the first two or three practice sessions, and plateau after that (Bartels et al., 2010; Collie et al., 2003), selective attention practice within and across modalities seems to have a particularly high practice potential with significant gains beyond three practice sessions, and in certain task conditions (i.e., in the visual 2-back and auditory 1back task) even beyond four sessions. As mentioned above, an exception to this age-independent pattern of practice gains was observed in the auditory 2-back task, in which older adults demonstrated slightly lower gains than their younger counterparts. A possible explanation for this observation is that the auditory 2-back task is a comparatively difficult task, as suggested by the relatively long reaction times and low accuracies. As a result, practice may have been more effortful for older individuals leading to lower practice gains.

The effects of distraction were largely confined to the unimodal conditions in both age groups. Remarkably, older adults were not disproportionally affected by unimodal visual or auditory distraction. This finding, which was independent of task modality and memory load, stands in stark contrast with existing accounts of age-related impairments of unimodal selective attention (Helfer \& Vargo, 2009; van der Lubbe \& Verleger, 2002; Wurm, Labouvie-Vief, Aycock, Rebucal, \& Koch, 2004). It suggests that the ability of older adults to inhibit unimodal distraction may be better preserved than previously thought (Guerreiro et al., 2010).

The only situation in which performance of the older participants was disproportionately affected was in the auditory 1-back task with visual distraction. This observation is a replication of two independent studies by Guerreiro and colleagues (Guerreiro et al., 2013; Guerreiro \& Van Gerven, 2011). The current study further substantiates this specific age-related impairment. Remarkably, this impairment did not affect the performance gain from practice, which suggests that age-related distractibility is independent of the ability to achieve practice gains in selective attention. At the same time, it is suggested that the specific age-related deficit in cross-modal auditory selective attention cannot be mitigated by repeated practice. It is remarkable, however, that this age effect on unimodal visual distraction is only visible in the 1-back, and not in the 2-back, task. This finding stands in contrast with previous work by Guerreiro et al. (2013), who documented age-related vulnerability to distraction independent of memory load. A possible explanation is that attention is more easily drawn away in relatively simple tasks. In contrast, more demanding tasks may make it easier to focus on relevant information and ignore distractors. Older individuals may be particularly vulnerable to this effect and less susceptible to cross-modal visual distraction under conditions where more attention is required by the primary task.

In sum, older adults improve their response speed on the selective attention task roughly at the same rate as younger adults do. However, they show a specific vulnerability regarding cross-modal visual distraction in 1-back conditions, which is not mitigated by practice. A slightly different pattern of results was observed with regard to accuracy. In line with the results from the reaction time data, older participants showed a specific vulnerability to cross-modal visual distraction. However, contrary to what we found for the reaction times, this age-related distraction effect was nullified after three practice sessions. Because the accuracy data of the younger participants were uninterpretable due to ceiling effects, the practice gains in the older sample need to be interpreted with caution. To avoid ceiling effects in the future, it may be recommendable to use a more difficult task (e.g., a 3back task) for investigating practice effects, especially if healthy young participants are involved.

While the specific vulnerability of older participants to cross-modal visual distraction was consistently observed, it remains difficult to interpret why this was specifically demonstrated in the 1-back task for RTs and in the 2-back task for the accuracy data. One possible explanation is that the focus of participants in the easier 1-back task lies more on speed, whereas in more demanding tasks, speed might become a subordinate goal, particularly in older participants. As a consequence, underlying difficulties might manifest clearest under these conditions.

Even though selective attention can be considered an essential prestage of further cognitive processing, no transfer of practice gains was observed in the current study. This contrasts with the transfer effects from selective attention training that were found by Mozolic et al. (2011). A possible explanation for this lack of transfer is that the control group in the current study performed the same working memory tasks without distraction. This may have made the treatment of the two groups too similar to induce measurable transfer to neuropsychological task performance. Note, however, that the training program employed by Mozolic and colleagues encompassed a multitude of cognitive tasks with distraction, including categorization, sorting, and mathematical operations, each of which could have led to transfer independent of the effect of selective attention per se. The strength of the current design is that it has shown us that it is not the training of selective attention that 
leads to transfer.

In summary, the conclusions from our study are threefold. First, our results suggest that older individuals have a high capacity to improve their selective attention performance within and across sensory modalities towards a level that is comparable to younger people's performance. Second, our findings corroborate the age-related deficit of crossmodal auditory selective attention that was found earlier (Guerreiro et al., 2013; Guerreiro \& Van Gerven, 2011). Finally, we have shown that this specific age-related impairment can be remediated by practice.

\section{Conflict of interest statement}

\section{Declarations of interest: none.}

\section{Acknowledgements}

We thank Nikita van de Burgt and Joyce Mertens for their substantial contributions to the data collection of this study. This study was supported by the Netherlands Organisation for Scientific Research (NWO; grant no. 406-14-057).

\section{References}

Allen, P. A., Lien, M.-C., Ruthruff, E., \& Voss, A. (2014). Multitasking and aging: Do older adults benefit from performing a highly practiced task? Experimental Aging Research, 40, 280-307. https://doi.org/10.1080/0361073X.2014.896663.

Andrés, P., Parmentier, F. B. R., \& Escera, C. (2006). The effect of age on involuntary capture of attention by irrelevant sounds: A test of the frontal hypothesis of aging. Neuropsychologia, 44, 2564-2568. https://doi.org/10.1016/j.neuropsychologia.2006. 05.005.

Bartels, C., Wegrzyn, M., Wiedl, A., Ackermann, V., \& Ehrenreich, H. (2010). Practice effects in healthy adults: A longitudinal study on frequent repetitive cognitive testing. BMC Neuroscience, 11, 118. https://doi.org/10.1186/1471-2202-11-11.

Barth, B., Strehl, U., Fallgatter, A. J., \& Ehlis, A.-C. (2016). Near-infrared spectroscopy based neurofeedback of prefrontal cortex activity: A proof-of-concept study. Frontiers in Human Neuroscience, 10. https://doi.org/10.3389/fnhum.2016.00633.

Belchior, P., Marsiske, M., Sisco, S. M., Yam, A., Bavelier, D., Ball, K., \& Mann, W. C. (2013). Video game training to improve selective visual attention in older adults. Computers in Human Behavior, 29, 1318-1324.

Claus, J. J., Mohr, E., \& Chase, T. N. (1991). Clinical trials in dementia: Learning effects with repeated testing. Journal of Psychiatry and Neuroscience, 16, 1-4.

Collie, A., Maruff, P., Darby, D. G., \& McStephen, M. (2003). The effects of practice on the cognitive test performance of neurologically normal individuals assessed at brief testretest intervals. Journal of the International Neuropsychological Society, 9, 419-428. https://doi.org/10.1017/S135561770393007.

Collier, R. O., Baker, F. B., Mandeville, G. K., \& Hayes, T. F. (1967). Estimates of test size for several test procedures based on conventional variance ratios in the repeated measures design. Psychometrika, 32, 339-353. https://doi.org/10.1007/ BF022895964.

Davis, A. (1995). Hearing in adults. Nottingham, England: Whurr.

Diederich, A., Colonius, H., \& Schomburg, A. (2008). Assessing age-related multisensory enhancement with the time-window-of-integration model. Neuropsychologia, 46, 2556-2562. https://doi.org/10.1016/j.neuropsychologia.2008.03.026.

Einstein, G. O., Earles, J. L., \& Collins, H. M. (2002). Gaze aversion spared inhibition for visual distraction in older adults. Journals of Gerontology. Series B, Psychological Sciences and Social Sciences, 57, P65-P73. https://doi.org/10.1093/geronb/57.1.P65.

Faul, F., Erdfelder, E., Lang, A.-G., \& Buchner, A. (2007). G*Power 3: A flexible statistical power analysis program for the social, behavioral, and biomedical sciences. Behavior Research Methods, 39, 175-191.

Foley, J. A., Cocchini, G., Logie, R. H., \& Sala, S. D. (2015). No dual-task practice effect in Alzheimer's disease. Memory, 23, 518-528. https://doi.org/10.1080/09658211. 2014.908922.

Fozard, J. L., \& Gordon-Salant, S. (2001). Changes in vision and hearing with aging. In J. E. Birren, \& K. W. Schaie (Eds.). Handbook of the psychology of aging (pp. 241-266). (5th ed.). San Diego: Academic Press.

Gazzaley, A., Cooney, J. W., McEvoy, K., Knight, R. T., \& D'Esposito, M. (2005). Top-down enhancement and suppression of the magnitude and speed of neural activity. Journal of Cognitive Neuroscience, 17, 507-517. https://doi.org/10.1162/ 0898929053279522.

Guerreiro, M. J. S., Adam, J. J., \& Van Gerven, P. W. M. (2014). Aging and response interference across sensory modalities. Psychonomic Bulletin \& Review, 21, 836-842. https://doi.org/10.3758/s13423-013-0554-5.

Guerreiro, M. J. S., Murphy, D. R., \& Van Gerven, P. W. M. (2010). The role of sensory modality in age-related distraction: A critical review and a renewed view. Psychological Bulletin, 136, 975-1022. https://doi.org/10.1037/a0020731.

Guerreiro, M. J. S., Murphy, D. R., \& Van Gerven, P. W. M. (2013). Making sense of agerelated distractibility: The critical role of sensory modality. Acta Psychologica, 142, 184-194. https://doi.org/10.1016/j.actpsy.2012.11.007.

Guerreiro, M. J. S., \& Van Gerven, P. W. M. (2011). Now you see it, now you don't:
Evidence for age-dependent and age-independent cross-modal distraction. Psychology and Aging, 26, 415-426. https://doi.org/10.1037/a0021507.

Guerreiro, M. J. S., \& Van Gerven, P. W. M. (2017). Disregarding hearing loss leads to overestimation of age-related cognitive decline. Neurobiology of Aging, 56, 180-189. https://doi.org/10.1016/j.neurobiolaging.2017.05.001.

Hasher, L., \& Zacks, R. T. (1988). Working memory, comprehension, and aging: A review and a new view. In G. H. Bower (Vol. Ed.), Psychology of learning and motivation. Vol. 22. Psychology of learning and motivation (pp. 193-225). Academic Press. https://doi. org/10.1016/S0079-7421(08)60041-9.

Helfer, K. S., \& Vargo, M. (2009). Speech recognition and temporal processing in middleaged women. Journal of the American Academy of Audiology, 20, 264-271. https://doi. org/10.3766/jaaa.20.4.6.

Jaeggi, S. M., Buschkuehl, M., Perrig, W. J., \& Meier, B. (2010). The concurrent validity of the N-back task as a working memory measure. Memory, 18, 394-412. https://doi. org/10.1080/09658211003702171.

Laurienti, P. J., Burdette, J. H., Maldjian, J. A., \& Wallace, M. T. (2006). Enhanced multisensory integration in older adults. Neurobiology of Aging, 27, 1155-1163. https://doi.org/10.1016/j.neurobiolaging.2005.05.024.

Leiva, A., Andres, P., \& Parmentier, F. (2015). When aging does not increase distraction: Evidence from pure auditory and visual oddball tasks. Journal of Experimental Psychology. Human Perception and Performance, 41, 432-442. https://doi.org/10. 1037/xhp0000112.

Leiva, A., Parmentier, F., \& Andres, P. (2014). Aging increases distraction by auditory oddballs in visual, but not auditory tasks. Psychological Research, 79, 396-410. https://doi.org/10.1007/s00426-014-0573-5.

Li, S. C., Schmiedek, F., Huxhold, O., Röcke, C., Smith, J., \& Lindenberger, U. (2008). Working memory plasticity in old age: Practice gain, transfer, and maintenance. Psychology and Aging, 23, 731-742. https://doi.org/10.1037/a0014343.

Li, X., Allen, P. A., Lien, M.-C., \& Yamamoto, N. (2017). Practice makes it better: A psychophysical study of visual perceptual learning and its transfer effects on aging. Psychology and Aging, 32, 16-27. https://doi.org/10.1037/pag0000145.

Lindenberger, U., \& Baltes, P. B. (1995). Testing-the-limits and experimental simulation: Two methods to explicate the role of learning in development. Human Development, 38, 349-360. https://doi.org/10.1159/000278341.

Lindenberger, U., Kliegl, R., \& Baltes, P. B. (1992). Professional expertise does not eliminate age differences in imagery-based memory performance during adulthood. Psychology and Aging, 7, 585-593. https://doi.org/10.1037/0882-7974.7.4.585.

Lustig, C., Hasher, L., \& Tonev, S. T. (2001). Inhibitory control over the present and the past. The European Journal of Cognitive Psychology, 13, 10.1080/ 09541440042000241107-122.

Lustig, C., Hasher, L., \& Zacks, R. (2007). Inhibitory deficit theory: Recent developments in a new view. In C. M. MacLeod, \& D. S. Gorfein (Eds.). Inhibition in cognition (pp. 145-162). Washington, DC: American Psychological Association. https://doi.org/10. 1037/11587-008.

Maaijwee, K., Mulder, P., Radner, W., \& Van Meurs, J. C. (2008). Reliability testing of the Dutch version of the Radner Reading Charts. Optometry and Vision Science, 85, 353-358. https://doi.org/10.1097/OPX.0b013e31816bf58b.

Maaijwee, K. J., Meulendijks, C. F., Radner, W. van Meurs, J. C., \& Hoyng, C. B. (2007) De Nederlandse versie van de Radner-leeskaart voor het beoordelen van de functionele visus [The Dutch version of the Radner Reading Chart for assessing vision function]. Nederlands Tijdschrift voor Geneeskunde, 151, 2494-2497.

Machulda, M. M., Pankratz, V. S., Christianson, T. J., Ivnik, R. J., Mielke, M. M., Roberts, R. O., ... Petersen, C, R. (2013). Practice effects and longitudinal cognitive change in normal aging vs. incident mild cognitive impairment and dementia in the Mayo Clinic study of aging. The Clinical Neuropsychologist, 27, 1247-1264. https://doi.org/10. 1080/13854046.2013.836567.

Maquestiaux, F., Laguë-Beauvais, M., Ruthruff, E., Hartley, A., \& Bherer, L. (2010). Learning to bypass the central bottleneck: Declining automaticity with advancing age. Psychology and Aging, 25, 177-192. https://doi.org/10.1037/a0017122.

Mayas, J., Parmentier, F. B. R., Andrés, P., \& Ballesteros, S. (2014). Plasticity of attentional functions in older adults after non-action video game training: A randomized controlled trial. PLoS One, 9, e92269. https://doi.org/10.1371/journal.pone. 0092269.

McGovern, D. P., Roudaia, E., Stapleton, J., McGinnity, T. M., \& Newell, F. N. (2014). The sound-induced flash illusion reveals dissociable age-related effects in multisensory integration. Frontiers in Aging Neuroscience, 6. https://doi.org/10.3389/fnagi.2014. 00250.

Mozolic, J. L., Long, A. B., Morgan, A. R., Rawley-Payne, M., \& Laurienti, P. J. (2011). A cognitive training intervention improves modality-specific attention in a randomized controlled trial of healthy older adults. Neurobiology of Aging, 32, 655-668. https:// doi.org/10.1016/j.neurobiolaging.2009.04.013.

Nasreddine, Z. S., Phillips, N. A., Bédirian, V., Charbonneau, S., Whitehead, V., Collin, I., et al. (2005). The Montreal Cognitive Assessment, MoCA: A brief screening tool for mild cognitive impairment. Journal of the American Geriatrics Society, 53, 695-699. https://doi.org/10.1111/j.1532-5415.2005.53221.

Reijnders, J., van Heugten, C., \& van Boxtel, M. (2013). Cognitive interventions in healthy older adults and people with mild cognitive impairment: A systematic review. Ageing Research Reviews, 12, 263-275. https://doi.org/10.1016/j.arr.2012.07.003.

Setti, A., Burke, K. E., Kenny, R. A., \& Newell, F. N. (2011). Is inefficient multisensory processing associated with falls in older people? Experimental Brain Research, 209, 375-384. https://doi.org/10.1007/s00221-011-2560-z.

Strobach, T., Frensch, P., Müller, H., \& Schubert, T. (2012). Age- and practice-related influences on dual-task costs and compensation mechanisms under optimal conditions of dual-task performance. Aging, Neuropsychology, and Cognition, 19, 222-247. https://doi.org/10.1080/13825585.2011.630973.

Stroop, J. R. (1935). Studies of interference in serial verbal reactions. Journal of 
Experimental Psychology, 18, 643-662. https://doi.org/10.1037/h0054651.

Uttl, B., \& Graf, P. (1997). Color-Word Stroop test performance across the adult life span. Journal of Clinical and Experimental Neuropsychology, 19, 405-420. https://doi.org/ 10.1080/01688639708403869.

Van der Elst, W., Van Boxtel, M. P. J., Van Breukelen, G. J. P., \& Jolles, J. (2006). The Stroop Color-Word Test: Influence of age, sex, and education; and normative data for a large sample across the adult age range. Assessment, 13, 62-79. https://doi.org/10. $1177 / 1073191105283427$.

Van der Elst, W. V. D., Van Boxtel, M. P. J., Van Breukelen, G. J. P., \& Jolles, J. (2005). Rey's verbal learning test: Normative data for 1855 healthy participants aged 24-81 years and the influence of age, sex, education, and mode of presentation. Journal of the International Neuropsychological Society, 11, 290-302. https://doi.org/
$10.1017 /$ S1355617705050344.

van der Lubbe, R. H. J., \& Verleger, R. (2002). Aging and the Simon task.

Psychophysiology, 39, 100-110. https://doi.org/10.1111/1469-8986.3910100.

Van Gerven, P. W. M., \& Guerreiro, M. J. S. (2016). Selective attention and sensory modality in aging: Curses and blessings. Frontiers in Human Neuroscience, 10. https:// doi.org/10.3389/fnhum.2016.00147.

Vink, M., \& Jolles, J. (1985). A new version of the trail making test as an informationprocessing task. Journal of Clinical and Experimental Neuropsychology, 7, 126.

Wurm, L. H., Labouvie-Vief, G., Aycock, J., Rebucal, K. A., \& Koch, H. E. (2004). Performance in auditory and visual emotional Stroop tasks: A comparison of older and younger adults. Psychology and Aging, 19, 523-535. https://doi.org/10.1037/ 0882-7974.19.3.523. 